\title{
Diversity of Prokaryotic Microorganisms in Alkaline Saline Soil of the Qarhan Salt Lake Area in the Qinghai-Tibet Plateau
}

\author{
Yaqiong Wang ( $\nabla$ wangyaqiong727@163.com ) \\ Qinghai Minzu University \\ Guoyuan Bao \\ Qinghai Minzu University
}

\section{Research Article}

Keywords: alkaline saline soil, 16S rRNA gene, diversity, community structure

Posted Date: October 21st, 2021

DOI: https://doi.org/10.21203/rs.3.rs-966317/v1

License: (c) (i) This work is licensed under a Creative Commons Attribution 4.0 International License. Read Full License

Version of Record: A version of this preprint was published at Scientific Reports on March 1st, 2022. See the published version at https://doi.org/10.1038/s41598-022-07311-3. 


\begin{abstract}
Microbial metabolism is the driving force for biogeochemical cycles in the biosphere. The composition of microbial communities varies greatly in various ecological environments, particularly in extreme environments where animals and plants cannot survive. Unique microorganisms are often used as indicators to reflect environmental conditions, but the ecological reasons for the differences in microbial communities are still largely unknown. Here, we analyzed taxonomic and functional community profiles via high-throughput sequencing to determine the alkaline saline soil bacterial and archaeal communities in the Qarhan Salt Lake area in the Qinghai-Tibet Plateau. The results showed that Betaproteobacteria (Proteobacteria) and Halobacteria (Euryarchaeota) were most abundant in the soils of this area, which are most common in high salinity environments. Accordingly, microorganisms in this area that can adapt to local extremes often have functions such as chemoheterotrophy, aerobic chemoheterotrophy, nitrogen fixation, ureolysis, nitrate reduction, fermentation, methanogenesis, hydrogenotrophic methanogenesis, methanogenesis by $\mathrm{CO}_{2}$ reduction with $\mathrm{H}_{2}$, methanogenesis using formate, and dark hydrogen oxidation. There is no doubt that prokaryotic microorganisms in high salinity environments play an irreplaceable role in nitrogen and carbon cycling through special metabolic pathways.
\end{abstract}

\title{
Introduction
}

Extreme habitats, such as harsh conditions uninhabitable by most living organisms, offer a unique opportunity to assess the types of microorganisms and supplement our understanding of growth parameters and requirements ${ }^{1}$. Studies have shown that domain archaea and bacteria are very important in various hypersaline environments ${ }^{2-7}$, and have identified halophilic microorganisms involved in carbon, nitrogen and sulfur cycling ${ }^{8-11}$.

As expected, high-altitude and high-salt environments provide special habitats for a variety of species. Zhu et al. ${ }^{12}$ studied core bacterial communities associated with hypersaline environments in lake water and sediments from the Qaidam Basin. Liu et al.

${ }^{13}$ studied Gammaproteobacterial diversity and carbon utilization in response to salinity in lakes on the Qinghai-Tibetan Plateau. Zhong et al. ${ }^{14}$ studied the prokaryotic community structure driven by salinity and ionic concentrations in plateau lakes of the Tibetan Plateau. However, there are few studies on soil microorganisms in bare land and plant-covered saline-alkali land around salt lakes in this area, which is worthy of further investigations.

The Qaidam Basin, located in the northeastern Qinghai-Tibetan Plateau, covers an area of $1.2 \times 10^{5} \mathrm{~km}^{2}$ and has an average elevation of 2,800 m asl; several salt lakes are distributed in this inland closed basin ${ }^{15}$. The Qarhan Salt Lake is the largest playa in this basin, consists of ten modern salt lakes ${ }^{16}$, and is characterized by thick halite layers and abundant liquid beds rich in $\mathrm{K}^{+}$and $\mathrm{Mg}^{2+17}$. This area has an extremely arid desert climate; the mean annual temperature is $5.33^{\circ} \mathrm{C}$, the mean annual precipitation is approximately $24 \mathrm{~mm}$, the annual evaporation is approximately $3,564 \mathrm{~mm}$, the average wind speed is $4.3 \mathrm{~m} / \mathrm{s}$, and the relative moisture is $27.7 \%{ }^{18}$. Here, we present a study of the prokaryotic community of hypersaline soil in the Qarhan Salt Lake area, using high-throughput sequencing, and the ecological function of prokaryotes in this area. This study aims (1) to improve our current understanding of the prokaryotic community in a new inland hypersaline environment that has not been characterized previously and (2) provide clues about how microbes adapt to the extreme environments of high salinity at high altitudes.

\section{Results}

\section{Microbial community structure in soils around salt lakes}

Microbial community composition was investigated by high-throughput Illumina sequencing. The number of bacterial and archaeal sequences in the five samples were 205,563 and 283,308 , respectively. A total of 643 operational taxonomic units (OTUs) were recovered comprising of 611 and 32 bacterial and archaeal OTUs, respectively. The rarefaction curves of all samples were flat, indicating that the amount of sequencing data was sufficient (See Supplementary Fig. S1). 
The bacterial domain was divided into 18 phyla, 42 classes, 66 orders, 115 families, and 195 genera. The dominant bacterial phyla (relative abundance $>10 \%$ ) in the five samples belonged to Proteobacteria (85.08\%), followed by Bacteroidetes (10.37\%) and Firmicutes $(2.99 \%)$, these three bacterial phyla constituted more than $98 \%$ of all reads (Fig. $1 \mathrm{~A})$. The major classes were Betaproteobacteria (66.65\%), Alphaproteobacteria (16.01\%), Sphingobacteriia (5.17\%), Bacteroidia (4.24\%) and Gammaproteobacteria (2.18\%), which were among the top five of the total bacterial classes (Fig. 1B). At the order level, Burkholderiales (66.56\%) were found to be the most dominant, followed by Caulobacterales (9.75\%), Rhizobiales (5.61\%), Sphingobacteriales (5.17\%), and Bacteroidales (4.24\%) in total abundance (Fig. 1C). At the family level, Burkholderiaceae $(60.76 \%)$ was dominant among all bacterial families (Fig. 1D). Of these, several genera were frequently dominant, with proportions in total sequences of more than 1\% (Fig. 1E). Among the dominant genera, Burkholderia was found to be the most abundant (1 OTU, $50.77 \%$ of total sequences), followed by Phenylobacterium (1 OTU, 9.64\%), Ralstonia (2 OTUs, $8.47 \%$ ), Herbaspirillum (1 OTU, 5.43\%), Prevotella (80 OTUs, 3.41\%), Chitinophaga (1 OTU, 2.92\%), Bradyrhizobium (1 0TU, $2.49 \%$ ), Mesorhizobium (1 OTU, 2.17\%), Sediminibacterium (1 OTU, 2.16\%), and Cupriavidus (1 OTU, 1.52\%) (Fig. 1E). These ten dominant genera accounted for $88.98 \%$ of the total classified sequences.

All the archaea detected belonged to the phylum Euryarchaeota, including 3 classes, 6 orders, 7 families, and 15 genera. Of these 3 classes, Halobacteria was the most abundant, accounting for $90.63 \%$ of the total 32 OTUs, covering 223,081 sequences (78.74\% of total 283,308 reads), followed by Methanomicrobia (2 OTUs, 40,511 sequences (14.30\%)) and Methanobacteria (1 OTU, 19,716 sequences (6.96\%), Fig. 1F). Halobacteriales (51.30\%) dominated among all bacterial orders (Fig. 1G) and Halobacteriaceae (51.30\%) dominated among all bacterial families (Fig. 1H). At the genus level, the dominant archaeal genera (relative abundance $>10 \%$ ) were unclassified_Halobacteriaceae, unclassified_Halobacteria, and Methanomicrobium, each with a widely varying abundance. The subdominant genera (1-10\% relative abundance) consisted of Halorussus, Halovivax, Methanobrevibacter, Halalkalicoccus, unclassified_Methanoregulaceae, Salinarchaeum, unclassified_Natrialbaceae, and unclassified_Haloferacaceae. Other minor genera included Halomicrobium, Natronoarchaeum, Halorubellus, and Natronomonas, which constituted small percentages of community abundance (<1\%). (Fig. 1I)

Alpha diversity analysis revealed that bacterial and archaeal community richness (Chao1), diversity (Shannon and Simpson), and evenness (Shannoneven) varied widely among the samples (Table 1). In particular, the lowest bacterial richness, diversity, and evenness were samples from QSG4, and the highest richness was QSB, with the highest diversity and evenness being QSG1. For archaea, the lowest richness and diversity were samples from QSG1, the highest were samples from QSG2, the lowest evenness was QSB, and the highest was QSG1.

Table 1

Statistical analysis of microbial diversity in the soil around the Qarhan Salt Lake on the Qinghai-Tibet plateau

\begin{tabular}{|lllllllll|}
\hline Classification & Sample & Sequence number & OTUs & Chao & Shannon & Simpson & Coverage & Shannoneven \\
Bacteria & QSB & 42785 & 283 & 284.909 & 2.535 & 0.273 & 0.99984 & 0.449 \\
& QSG1 & 39352 & 266 & 266.857 & 2.690 & 0.216 & 0.99990 & 0.482 \\
& QSG2 & 44574 & 161 & 161.000 & 2.133 & 0.284 & 0.99998 & 0.420 \\
& QSG3 & 41922 & 272 & 272.500 & 2.529 & 0.239 & 0.99995 & 0.451 \\
\hline \multirow{3}{*}{ Archaea } & QSG4 & 36930 & 117 & 117.250 & 1.661 & 0.427 & 0.99995 & 0.349 \\
& QSB & 54738 & 10 & 10.000 & 1.647 & 0.240 & 1.00000 & 0.715 \\
& QSG1 & 54344 & 2 & 2.000 & 0.690 & 0.504 & 1.00000 & 0.995 \\
& QSG2 & 58870 & 20 & 20.000 & 2.570 & 0.095 & 0.99998 & 0.858 \\
& QSG3 & 52600 & 6 & 6.000 & 1.473 & 0.275 & 1.00000 & 0.822 \\
\hline
\end{tabular}




\section{Alkaline saline soil prokaryotic $\beta$-diversity}

Unweighted UniFrac distance metrics were used to estimate bacterial and archaeal $\beta$-diversity and to identify dissimilarities between the different samples. The principal coordinate analysis (PCOA) plot illustrated the dissimilarity of OTU composition; the first two principal components explained 79.18\% (PCoA 1 + PCoA 2; bacteria) and 79.18\% (PCoA $1+$ PCoA 2; archaea) of the total variation (Fig. 2). For the analysis of multivariate homogeneity among groups, the analysis of similarities (ANOSIM) test was performed, and the results showed that there were no significant differences between the bare land and the grassland ( $p>$ 0.05).

Bacteria from bare land and grassland shared 187 OTUs (Fig. 3A), and more unique OTUs (102) were recovered from QSG3, a number that exceeded the unique OTUs found in bare land QSB (96) (Fig. 3B). For archaea, bare land and grassland shared seven OTUs (Fig. 3C), more unique OTUs (15) were recovered from QSG2, a number that also exceeded the unique OTUs found in bare land QSB (3) (Fig. 3D).

\section{Potential correlations between microbial communities and soil variables}

RDA was performed to reveal the relationship between microbial community structures and the soil variables. The first two RDA axes explained $60.38 \%$ and $64.8 \%$ of the bacterial and archaeal community variations, respectively (See Supplementary Fig. S2).

Spearman's rank correlation test was performed to clarify the relationship between environmental factors and prokaryotic composition (relative abundance at the genus level) (Fig. 4). For bacteria, Ralstonia and Cupriavidus were positively correlated with $\mathrm{Mg}^{2+}$ and $\mathrm{K}^{+}$, but Mesorhizobium, Escherichia_Shigella, and Bradyrhizobium were negatively correlated with $\mathrm{Mg}^{2+}$ and $\mathrm{K}^{+}$; Burkholderia was negatively correlated with $\mathrm{Na}$, but Chitinophaga, Phenylobacterium and Mesorhizobium were positively correlated with the $\mathrm{Na}$, and Phenylobacterium and Mesorhizobium were negatively correlated with P (Fig. 4A). For archaea, Halovivax was positively correlated with $\mathrm{Mg}^{2+}$ and $\mathrm{K}^{+}$, Halomicrobium and Methanobrevibacter were negatively correlated with $\mathrm{Na}$, but positively correlated with P; Methanomicrobium was positively correlated with $\mathrm{Na}$ (Fig. 4B). These findings suggest that soil variables are important contributing factors for the regulation of soil prokaryotes.

\section{Co-occurrence network of dominant taxa among prokaryotic microorganisms}

A co-occurrence network was constructed to identify the possible assemblages existing among prokaryotic microorganism OTUs in alkaline saline soil. The core dominant taxa in the cluster were strongly correlated with each other $(|R|>0.8, p<0.05)$. Notably, the network depicted several keystone OTUs that were assigned to the phyla Bacteroidetes, genus Prevotella (OTU19, and OTU13), Proteobacteria (OTU9 - Cupriavidus, OTU3 - Ralstonia, OTU1 - Burkholderia, OTU5 - Mesorhizobium, OTU7 Herbaspirillum, and OTU2 - Phenylobacterium) (Fig. 5A). For archaeal taxa, including Halobacteria (OTU20, OTU8, and OTU17), Halobacteriaceae (OTU18, OTU29, OTU12, OTU25, OTU7, and OTU4), Haloferacaceae (OTU19), Natrialbaceae (OTU38, OTU24, OTU16, and OTU26), Methanoregulaceae (OTU9), Halorussus (OTU13 and OTU5), Halorubellus (OTU23), Salinarchaeum (OTU27), Halovivax (OTU3), Methanobrevibacter (OTU6), Halomicrobium (OTU21), and Natronoarchaeum (OTU22) (Fig. 5B).

The co-occurrence network is an effective way to reveal the relationship between individual group members and the entire ecosystem ${ }^{19,20}$. The co-occurrence network clusters suggest that core bacterial and archaeal taxa in alkaline saline soil are likely to collaborate with each other and play a role in key metabolic steps in response to environmental changes. (Fig. 5). Thus, study of physiological and metabolic characteristics belonging to these key species can help us understand the mechanisms of microbial adaptation to the environment. 


\section{Prediction of ecological function of prokaryotic microorganisms}

To gain insight into the ecological function of bacteria and archaea to alkaline saline soil, the prediction tools PICRUSt and FAPROTAX were used to determine the functional characteristics of the prokaryotic communities in the soil. Table 2 presents the number of sequence reads of the predicted genes involved in adaptation to a high-salt environment.

Table 2

Metabolic enzymes for which cellular abundance was related to adaptation to high-salt conditions. 


\begin{tabular}{|c|c|c|c|c|c|c|c|c|}
\hline \multirow[t]{2}{*}{ Taxa } & \multirow[t]{2}{*}{ Enzyme No. } & \multirow{2}{*}{$\begin{array}{l}\text { KEGG } \\
\text { No. }\end{array}$} & \multirow[t]{2}{*}{ Type of enzyme } & \multicolumn{5}{|c|}{ Abundance } \\
\hline & & & & QSB & QSG1 & QSG2 & QSG3 & QSG4 \\
\hline \multirow[t]{23}{*}{ Bacteria } & 1.4.1.13/1.4.1.14 & K00266 & $\begin{array}{l}\text { glutamate synthase } \\
\text { (NADPH/NADH) small chain }\end{array}$ & 30397 & 30001 & 33352 & 31344 & 26406 \\
\hline & 6.3.1.2 & K01915 & glutamine synthetase & 26337 & 26850 & 31833 & 27808 & 23459 \\
\hline & 1.2.1.8 & K00130 & $\begin{array}{l}\text { betaine-aldehyde } \\
\text { dehydrogenase }\end{array}$ & 24450 & 19588 & 25485 & 22474 & 25803 \\
\hline & 1.5.3.1 & K00303 & $\begin{array}{l}\text { sarcosine oxidase, subunit } \\
\text { beta }\end{array}$ & 10861 & 8942 & 12185 & 10113 & 10499 \\
\hline & 1.5.1.2 & K00286 & $\begin{array}{l}\text { pyrroline-5-carboxylate } \\
\text { reductase }\end{array}$ & 10282 & 10506 & 11645 & 10995 & 8691 \\
\hline & 1.4.1.13/1.4.1.14 & K00265 & $\begin{array}{l}\text { glutamate synthase } \\
(\mathrm{NADPH} / \mathrm{NADH} \text { ) large chain }\end{array}$ & 9881 & 10661 & 11912 & 11643 & 7185 \\
\hline & 2.7.7.42 & K00982 & $\begin{array}{l}\text { glutamate-ammonia-ligase } \\
\text { adenylyltransferase }\end{array}$ & 8380 & 7815 & 9945 & 8467 & 7853 \\
\hline & 1.4.1.2 & K00260 & glutamate dehydrogenase & 6967 & 6655 & 8671 & 7069 & 6739 \\
\hline & 1.4.1.3 & K00261 & $\begin{array}{l}\text { glutamate dehydrogenase } \\
(\mathrm{NAD}(\mathrm{P})+)\end{array}$ & 7014 & 6237 & 7835 & 7698 & 6566 \\
\hline & 1.5.3.1 & K00302 & $\begin{array}{l}\text { sarcosine oxidase, subunit } \\
\text { alpha }\end{array}$ & 6707 & 5610 & 7793 & 6285 & 6074 \\
\hline & 1.5.3.1 & K00304 & $\begin{array}{l}\text { sarcosine oxidase, subunit } \\
\text { delta }\end{array}$ & 6678 & 5590 & 7723 & 6244 & 6078 \\
\hline & 1.5.3.1 & K00305 & $\begin{array}{l}\text { sarcosine oxidase, subunit } \\
\text { gamma }\end{array}$ & 6224 & 5161 & 7112 & 5809 & 5746 \\
\hline & 3.6.3.32 & K02000 & $\begin{array}{l}\text { glycine betaine/proline } \\
\text { transport system ATP-binding } \\
\text { protein }\end{array}$ & 5905 & 4772 & 6228 & 5528 & 5424 \\
\hline & 3.1.3.12 & K01087 & trehalose-phosphatase & 5640 & 4492 & 6090 & 5153 & 5230 \\
\hline & 3.1.6.6 & K01133 & choline-sulfatase & 4959 & 4072 & 5275 & 4672 & 4815 \\
\hline & 1.4.7.1 & K00284 & $\begin{array}{l}\text { glutamate synthase } \\
\text { (ferredoxin) }\end{array}$ & 3810 & 3187 & 4049 & 3581 & 4117 \\
\hline & 1.5.3.1 & K00301 & sarcosine oxidase & 2319 & 2942 & 3882 & 2762 & 2178 \\
\hline & 1.4.1.4 & K00262 & $\begin{array}{l}\text { glutamate dehydrogenase } \\
(\mathrm{NADP}+)\end{array}$ & 2850 & 2865 & 1420 & 2223 & 869 \\
\hline & 1.14.11.- & K00674 & ectoine hydroxylase & 227 & 508 & 704 & 647 & 205 \\
\hline & 3.2.1.93 & K01226 & $\begin{array}{l}\text { trehalose-6-phosphate } \\
\text { hydrolase }\end{array}$ & 150 & 96 & 48 & 35 & 5 \\
\hline & 4.2.1.108 & K06720 & L-ectoine synthase & 107 & 38 & 37 & 71 & 64 \\
\hline & 2.3.1.178 & K06718 & $\begin{array}{l}\text { L-2,4-diaminobutyric acid } \\
\text { acetyltransferase }\end{array}$ & 103 & 38 & 37 & 55 & 61 \\
\hline & 1.5.3.1/1.5.3.7 & K00306 & $\begin{array}{l}\text { sarcosine oxidase / L- } \\
\text { pipecolate oxidase }\end{array}$ & 0 & 0 & 0 & 12 & 0 \\
\hline \multirow[t]{2}{*}{ Archaea } & 1.4.1.3 & K00261 & $\begin{array}{l}\text { glutamate dehydrogenase } \\
(\operatorname{NAD}(P)+)\end{array}$ & 35517 & 44521 & 82617 & 112244 & 57820 \\
\hline & 6.3.1.2 & K01915 & glutamine synthetase & 35133 & 59573 & 35278 & 50496 & 34394 \\
\hline
\end{tabular}




\begin{tabular}{|c|c|c|c|c|c|c|c|}
\hline 1.4.1.13/1.4.1.14 & K00265 & $\begin{array}{l}\text { glutamate synthase } \\
(\mathrm{NADPH} / \mathrm{NADH}) \text { large chain }\end{array}$ & 26151 & 19646 & 62308 & 53274 & 49897 \\
\hline 1.5.3.1 & K00303 & $\begin{array}{l}\text { sarcosine oxidase, subunit } \\
\text { beta }\end{array}$ & 20100 & 9823 & 36957 & 61074 & 24948 \\
\hline 1.5.1.2 & K00286 & $\begin{array}{l}\text { pyrroline-5-carboxylate } \\
\text { reductase }\end{array}$ & 20592 & 34698 & 17267 & 14484 & 17282 \\
\hline 3.1 .6 .6 & K01133 & choline-sulfatase & 15417 & 9823 & 20790 & 31252 & 17282 \\
\hline 1.4.1.13/1.4.1.14 & K00266 & $\begin{array}{l}\text { glutamate synthase } \\
\text { (NADPH/NADH) small chain }\end{array}$ & 0 & 49750 & 0 & 12380 & 9446 \\
\hline 3.1.3.12 & K01087 & trehalose-phosphatase & 4683 & 0 & 14914 & 29822 & 7667 \\
\hline 1.2.1.8 & K00130 & $\begin{array}{l}\text { betaine-aldehyde } \\
\text { dehydrogenase }\end{array}$ & 4683 & 0 & 12724 & 29822 & 7667 \\
\hline 3.6.3.32 & K02000 & $\begin{array}{l}\text { glycine betaine/proline } \\
\text { transport system ATP-binding } \\
\text { protein }\end{array}$ & 0 & 24875 & 0 & 6190 & 4723 \\
\hline 1.5.3.1 & K00301 & sarcosine oxidase & 0 & 0 & 12265 & 6864 & 7667 \\
\hline 1.4.1.4 & K00262 & $\begin{array}{l}\text { glutamate dehydrogenase } \\
(\mathrm{NADP}+)\end{array}$ & 9858 & 0 & 0 & 0 & 0 \\
\hline 1.4.1.2 & K00260 & glutamate dehydrogenase & 0 & 0 & 459 & 0 & 256 \\
\hline
\end{tabular}

The OTUs detected in all samples were compared with FAPROTAX annotation rule in an automated manner; however, most OTUs could not be assigned to any functional group. Thus, only those OTUs that were successfully annotated were analyzed. Chemoheterotrophy, aerobic chemoheterotrophy, nitrogen fixation, ureolysis, nitrate reduction, fermentation, predatory or exoparasitic were the most abundance bacterial functional groups (Fig. 6A). Methanogenesis, hydrogenotrophic methanogenesis, methanogenesis by $\mathrm{CO}_{2}$ reduction with $\mathrm{H}_{2}$, chemoheterotrophy, methanogenesis using formate, dark hydrogen oxidation, nitrate reduction, and aerobic chemoheterotrophy were the most abundance archaeal functional groups (Fig. 6B). These functional groups provide directions for understanding the mechanisms of adaptation of prokaryotes to high salinity environments.

The metabolic pathways of microbial consortia predicted by PICRUSt were further analyzed. Metabolic pathways were identified at three levels. Functions of bacteria and archaea related to high-salt environment in level 1 include cellular processes (4.19$4.31 \%, 1.78-3.99 \%)$, environmental information processing (15.87-17.12\%, 10.74-12.55\%), genetic information processing (13.44-14.32\%, 17.18-18.99\%), and metabolism (49.29-49.62\%, 46.69-52.02\%). The distribution of bacterial and archaeal functions at level 2 was further analyzed. For bacteria, the relative abundances of membrane transport, amino acid metabolism, carbohydrate metabolism, and replication and repair were enriched in the alkaline saline soil, and there was not much difference between the samples (Fig. 7A). However, for archaea, the relative abundances of amino acid metabolism, carbohydrate metabolism, membrane transport, energy metabolism, and translation were enriched in alkaline saline soil, and there was a great deal of variation among samples (Fig. 7B). It is reasonable that bacteria and archaea may adopt different strategies when coping with extreme environments, and the bacterial community is relatively stable, while the archaea community is quite different.

\section{Discussion}

Metagenomic technology is a powerful tool to explore microorganisms in extreme habitats and their environmental adaptation mechanisms ${ }^{21}$. Using this technique, we found that the predominant phyla within the bacterial communities were Proteobacteria (85.08\%), followed by Bacteroidetes (10.37\%), Firmicutes (2.99\%), and Actinobacteria (0.34\%), and Proteobacteria were ubiquitous across all samples in the soil of the Qarhan Salt Lake area (Fig. 1A). Numerous studies have shown that the bacterial communities are dominated by Proteobacteria, followed by Firmicutes, Bacteroidetes, Cyanobacteria, 
Actinobacteria, and Verrucomicrobia ${ }^{12,22,23}$. Among the Proteobacteria, Alpha- (16.01\%), Beta- (66.65\%), Gamma- (2.18\%), and Delta-Proteobacteria (0.18\%) were detected in all samples (Fig. 1B). These taxa were formerly verified in other hypersaline environments ${ }^{14,24-26}$, consistent with the results of this study, Betaproteobacteria were dominant in the salt water and sediments from Chott El Jerid Lake (75-95\%) ${ }^{23}$, and some other studies proved that Gammaproteobacteria ${ }^{12,13,27}$ and Alphaproteobacteria were the dominant classes ${ }^{28}$.

Bacteroidetes was the second most abundant phylum; it has been reported to be associated with nutrient conversion in lake sediments 29,30 , and the relative abundance of this phylum is strongly correlated with the salinity gradient in inland lakes 14,31-33. The network revealed two keystone OTUs that were assigned to the phyla Bacteroidetes, genus Prevotella (OTU19, and OTU13). Figure 5, combined with the abundance and wide distribution indicates its ecological importance in the alkaline saline soil.

Similar to our findings, the phyla Firmicutes and Actinobacteria were also occurs in hypersaline environments ${ }^{23,34}$. Because Actinobacteria can decompose cellulose and other organic materials in hypersaline environments ${ }^{35}$. Thus, it can be seen the ecological role of Actinobacteria is particularly important in saline-alkali land covered by vegetation.

The top ten bacterial genera ( $>1 \%$ of all sequences) representing $88.98 \%$ of the microbial community. Burkholderia was the most abundant, followed by Phenylobacterium and Ralstonia (Fig. 1E). Consistent with other studies ${ }^{23}$, Burkholderia prevailed in our samples and it has previously been reported to degrade aromatic hydrocarbons ${ }^{36}$. Ralstonia was also a common taxa in hypersaline environments $23,37,38$.

Archaea are extensively involved in the carbon and nitrogen cycles (Schleper et al. 2005; Cavicchioli 2006; Leininger et al. 2006) 39. The results showed that archaea in the soil near Qarhan Salt Lake were dominated by Halobacteria (Fig. 1F), Previous study also showed that Halobacteria dwell in salt lakes and salterns and can propagate in salt crystals ${ }^{26}$.

Halobacteriaceae (51.30\%) was the dominant family in these samples (Fig. 1H), which is consistent with the studies of archaea from Ebinur Lake Wetland ${ }^{40}$, heavy metal-contaminated soils ${ }^{41}$, salt pans around Bhavnagar Coast ${ }^{42}$, inland saltern ecosystems in the Alto Vinalopó Valley ${ }^{43}$ and Lake Gasikule of the Tibetan Plateau ${ }^{14}$. These results showed that Halobacteriaceae was the dominant family in most terrestrial high-salt environments. Halobacteriaceae can accumulate large quantities of inorganic ions $\left(\mathrm{K}^{+}, \mathrm{Na}^{+}, \mathrm{C1}^{-}\right)$, and their intracellular proteins and macromolecules are not damaged by high intracellular salt concentrations ${ }^{44}$, thus ensuring their survival in high salt environment, and exist as a dominant microbiota.

The composition of archaea at the genus level varied greatly among different samples (Fig. 1I). In particular, Methanomicrobium dominated in samples QSG1 and QSG3; Methanobrevibacter dominated in sample QSB, which is rare in other related studies. Nevertheless, the core genus is significantly different from other high salt environments and represents a relatively unique archaea community. However, the number of unannotated archaea (56.96\%) is noteworthy.

Network interactions between taxa can capture ecological community habitat preference and taxa interactions 45,46 . Statistically, in our prokaryotic microorganisms in the alkaline saline soil of the Qarhan Salt Lake area, several keystone OTUs with high degrees were identified (Fig. 5), indicating that these OTUs could make a crucial difference in the soil microbial ecosystem. The metabolism of these keystone taxa is likely to be critical for the stability of the entire ecosystem, maintaining a fragile ecological balance in high-altitude and high-salt environments. Thus, the dynamics of any identified keystone OTUs could significantly affect this ecosystem.

Most of the bacterial and archaeal species in the microbial community in the alkaline saline soil of the Qarhan Salt Lake area had genes in the synthesis of halo-adaptation compounds such as ectoine, glycine betaine, glutamate, trehalose, and choline (Table 2). This result, similar to a study of bacterial communities in Lake Tuz, indicates that the unique cellular enzymatic machinery of halophilic microbes allows them to effectively use hydrocarbons as their sole source of both carbon and energy 47. 


\section{Methods}

\section{Sample collection}

The sampling site is located around the Qarhan Salt Lake (36 $36^{\prime} 57^{\prime \prime} \mathrm{N}, 95^{\circ} 11^{\prime} 24^{\prime \prime} \mathrm{E}$; Altitude 2,651 m) in the state of QinghaiTibet Plateau, China. Soil samples were collected during summer, on July 14,2020 , at a temperature of $22^{\circ} \mathrm{C}$.

Five soil samples were collected; one from bare land (QSB) and the other four from the grassland (QSG1, QSG2, QSG3, and QSG4), and the distance from one sample to the next was $100 \mathrm{~m}$. Five sub-samples $(100 \mathrm{~g})$ were taken from the 0 to $10 \mathrm{~cm}$ layer with a hand spade, pooled, homogeneous mixed to one sample (500 g), and taken to the laboratory. The samples were sieved with a $5 \mathrm{~mm}$ test sieve (WSTYLER, USA) under aseptic conditions. Part of the soil $(250 \mathrm{~g})$ was used to characterize soil properties, while the rest $(250 \mathrm{~g})$ were stored at $-80^{\circ} \mathrm{C}$ for sequencing. The contents of various elements in the soil samples were determined using the ZSX Primus IV X-ray fluorescence spectrometer (Rigaku, Japan) according to the manufacturer's instructions, and the results are summarized in Supplementary Table S1.

\section{DNA Extraction, PCR. and sequencing}

Total genomic DNA (gDNA) from soil samples ( 500 mg) was extracted using the E.Z.N.A ( $^{\text {M }}$ Mag-Bind Soil DNA Kit (OMEGA Bio-Tek, USA). DNA yield was quantified with the Qubit3.0 DNA Test Kit (Life Technologies, USA). Purified DNA was used as the template for the amplification of $16 \mathrm{~S}$ rDNA genes via polymerase chain reaction (PCR). Approximately 10-20 ng of gDNA was used as a PCR template for amplification.

There were two rounds of nested PCR amplification for archaea. For the first round, the reaction mixture (30 $\mu L)$ contained 10$20 \mathrm{ng}$ of gDNA, the appropriate primers at $1 \mu \mathrm{L}$ each, and 2xHieff® Robust PCR Master Mix (Yeasen Biotechnology, Shanghai, China) $15 \mu \mathrm{L}$. The archaeal-specific primers used were GU1ST-340F (5'-CCCTAYGGGGYGCASCAG-3') and GU1ST-1000R (5'GGCCATGCACYWCYTCTC-3') ${ }^{48}$. Amplification conditions included a denaturation step for 3 min at $94^{\circ} \mathrm{C}$, followed by 5 cycles consisting of $30 \mathrm{~s}$ at $94^{\circ} \mathrm{C}, 20 \mathrm{~s}$ at $45^{\circ} \mathrm{C}, 30 \mathrm{~s}$ at $65^{\circ} \mathrm{C} ; 20$ cycles consisting of $20 \mathrm{~s}$ at $94^{\circ} \mathrm{C}, 20 \mathrm{~s}$ at $55^{\circ} \mathrm{C}, 30 \mathrm{~s}$ at $72^{\circ} \mathrm{C}$, and a final elongation step at $72^{\circ} \mathrm{C}$ for $5 \mathrm{~min}$. The $20-30 \mathrm{ng}$ of the PCR product in the first round was used as template DNA for the second PCR performed using the same PCR conditions and general V3-V4 primer set 349F (5'-GYGCASCAGKCGMGAAW-3'), 806R (5'GGACTACVSGGGTATCTAAT-3'), including a barcode on the forward primer.

For bacteria, the primers Nobar_341F (5'-CCTACGGGNGGCWGCAG-3') and primer Nobar_805R (5'-GACTACHVGGGTATCTAATCC$\left.3^{1}\right)^{48}$ were used in the PCR reaction, including a barcode on the forward primer. The PCR reactions were performed in $30 \mu \mathrm{L}$ reactions for denaturation at $94^{\circ} \mathrm{C}$ for $3 \mathrm{~min}$, followed by 5 cycles consisting of $30 \mathrm{~s}$ at $94^{\circ} \mathrm{C}, 20 \mathrm{~s}$ at $45^{\circ} \mathrm{C}, 30 \mathrm{~s}$ at $65^{\circ} \mathrm{C} ; 20$ cycles consisting of $20 \mathrm{~s}$ at $94^{\circ} \mathrm{C}, 20 \mathrm{~s}$ at $55^{\circ} \mathrm{C}, 30 \mathrm{~s}$ at $72^{\circ} \mathrm{C}$, and a final elongation step at $72^{\circ} \mathrm{C}$ for 5 min.

Subsequently, Illumina bridge PCR compatible primers were introduced and PCR was performed in $30 \mu L$ reactions containing 20-30 ng of PCR product of bacteria or archaea which was used as template DNA; the primer F $1 \mu L$; Index-PCR Primer R $1 \mu L$ and $2 \times$ Hieff ${ }^{\circ}$ Robust PCR Master Mix (Yeasen) $15 \mu \mathrm{L}$. The PCR reactions included denaturation at $95^{\circ} \mathrm{C}$ for 3 min, followed by 5 cycles of denaturation at $94^{\circ} \mathrm{C}$ for $20 \mathrm{~s}$, annealing at $55^{\circ} \mathrm{C}$ for $20 \mathrm{~s}$, extension at $72^{\circ} \mathrm{C}$ for $30 \mathrm{~s}$, and a final elongation step at $72^{\circ} \mathrm{C}$ for $5 \mathrm{~min}$.

PCR products were assessed by agarose gel electrophoresis. To obtain a uniform long cluster effect and high-quality sequencing data, the library concentration was determined using a Qubit 3.0 fluorometer (Invitrogen, USA). Subsequently, the amplicons were loaded onto an Illumina HiSeq platform (Illumina, Inc. San Diego, CA, USA), according to the manufacturer's guidelines.

\section{Bioinformatic and statistical analyses}


Sequences were analyzed using a combination of USEARCH 11.0.667 and QIIME v1.8.0 ${ }^{49}$. The sequencing primer connector of the Read $3^{\prime}$-end was removed from Cutadapt $1.18^{50}$. PEAR 0.9 .8 was used to merge pairs of reads into a sequence according to the overlap relationship between paired-end reads (PE reads) ${ }^{51}$. Barcodes were removed from the multiplexed FASTQ files using the USEARCH python command script fastq_strip_barcode_relabel2.py. PRINSEQ 0.20.4 was used to remove the bases with a tail mass value below 20 reads, and a window of 10 bp was set. If the average mass value in the window was lower than 20 , the back-end bases were cut off from the window to filter the $\mathrm{N}$-containing sequences and short sequences after quality control, and the low-complexity sequences were finally filtered out ${ }^{52}$. The FASTA files were de-replicated, and abundance sorted, and singleton sequences were removed. The OTUs were clustered de novo using Usearch 11.0.667 ${ }^{53}$. The OTUs were then mapped back to the original reads, and an OTU table was produced. Taxonomy was assigned to OTUs using the BLAST method in QIIME and against the RDP $16 \mathrm{~S}$ database 2.12: http://rdp.cme.msu.edu/misc/resources.jsp. Mothur 1.43 .0 was used to determine the alpha diversity index ${ }^{54}$. Principal component analysis was used to reflect the differences and distances between samples using the vegan $R$ package (v. 2.5-6).

The relative abundances of bacterial taxa were summarized using the Venn diagram package (v. 1.6.20) for $\mathrm{R}^{55}$.

OTU co-occurrence network analysis was conducted using the R graph package (v. 2.0.0) based on the Bray-Curtis distance metric. Redundancy analysis (RDA) was conducted to evaluate the association between community composition and environmental parameters using the RDA function of the vegan package for R (v.2.5-6) ${ }^{56}$. Correlation heat maps evaluate the correlation between microbial classification and environmental variables by $\mathrm{R}$ (v.3.3.0)

The functional potential of the microbial community was investigated using 16S rRNA abundance data via PICRUSt v.1.1.4 with default parameters ${ }^{57}$. The $16 \mathrm{~S}$ rRNA-based metagenome was functionally annotated using KEGG pathway functions using hidden state prediction ${ }^{58}$. The functional annotation of prokaryotic taxa via Functional Annotation of Prokaryotic Taxa (FAPROTAX) v.1.2.1 is available online at http://www.zoology.ubc.ca/louca/FAPROTAX ${ }^{59}$.

\section{Declarations}

\section{Acknowledgments}

This work was supported by the Natural Science Foundation of Qinghai (2019-ZJ-978Q).

\section{Author contributions}

Y.W. designed the research, prepared figures, analyzed the data, drafted the manuscript; G.B. performed the experiments. Both the authors reviewed the manuscript.

\section{Competing interests}

The authors declare that there are no competing interests.

\section{References}

1. Boutaiba, S., Hacene, H., Bidle, K. A. \& Maupin-Furlow, J. A. Microbial diversity of the hypersaline Sidi Ameur and Himalatt Salt Lakes of the Algerian Sahara. Journal of Arid Environments, 75, 909-916 https://doi.org/10.1016/j.jaridenv.2011.04.010 (2011).

2. Mutlu, M. B. et al. Prokaryotic diversity in Tuz Lake, a hypersaline environment in Inland Turkey. FEMS Microbiology Ecology, 65, 474-483 https://doi.org/10.1111/j.1574-6941.2008.00510.x (2008). 
3. Antón, J. et al. Distribution, abundance and diversity of the extremely halophilic bacterium Salinibacter ruber. Saline Systems, 4, 15 https://doi.org/10.1186/1746-1448-4-15 (2008).

4. Oren, A. Microbial life at high salt concentrations: phylogenetic and metabolic diversity. Saline Systems, 4, 2 https://doi.org/10.1186/1746-1448-4-2 (2008).

5. Abdeljabbar, H., Badiaa, E., Jean-Luc, C., Marie-Laure, F. \& Najla, S. Prokaryotic biodiversity of halophilic microorganisms isolated from Sehline Sebkha Salt Lake (Tunisia). African Journal of Microbiology Research, 8, 355-367 https://doi.org/10.5897/ajmr12.1087 (2014).

6. Kashi, F. J., Owlia, P., Amoozegar, M. A. \& Kazemi, B. Halophilic Prokaryotes in Urmia Salt Lake, a Hypersaline Environment in Iran.Current Microbiology(2021).

7. Najjari, A., Elshahed, M. S., Cherif, A., Youssef, N. H. \& Löffler, F. E. Patterns and Determinants of Halophilic Archaea (Class Halobacteria) Diversity in Tunisian Endorheic Salt Lakes and Sebkhet Systems. Applied and Environmental Microbiology, 81, 4432-4441 https://doi.org/10.1128/aem.01097-15 (2015).

8. Foti, M. et al. Diversity, Activity, and Abundance of Sulfate-Reducing Bacteria in Saline and Hypersaline Soda Lakes. Applied and Environmental Microbiology, 73, 2093-2100 https://doi.org/10.1128/aem.02622-06 (2007).

9. Boujelben, I. et al. Spatial and seasonal prokaryotic community dynamics in ponds of increasing salinity of Sfax solar saltern in Tunisia. Antonie van Leeuwenhoek, 101, 845-857 https://doi.org/10.1007/s10482-012-9701-7 (2012).

10. García-Maldonado, J. Q., Bebout, B. M., Everroad, R. C. \& López-Cortés, A. Evidence of Novel Phylogenetic Lineages of Methanogenic Archaea from Hypersaline Microbial Mats. Microb. Ecol, 69, 106-117 https://doi.org/10.1007/s00248-0140473-7 (2014).

11. Abed, R. M. M., de Beer, D. \& Stief, P. Functional-Structural Analysis of Nitrogen-Cycle Bacteria in a Hypersaline Mat from the Omani Desert. Geomicrobiol J, 32, 119-129 https://doi.org/10.1080/01490451.2014.932033 (2014).

12. Zhu, D. et al. An evaluation of the core bacterial communities associated with hypersaline environments in the Qaidam Basin, China. Archives of Microbiology, 202, 2093-2103 https://doi.org/10.1007/s00203-020-01927-7 (2020).

13. Liu, W., Jiang, H., Yang, J. \& Wu, G. Gammaproteobacterial Diversity and Carbon Utilization in Response to Salinity in the Lakes on the Qinghai-Tibetan Plateau. Geomicrobio/ J, 35, 392-403 https://doi.org/10.1080/01490451.2017.1378951 (2018).

14. Zhong, Z. P. et al. Prokaryotic Community Structure Driven by Salinity and lonic Concentrations in Plateau Lakes of the Tibetan Plateau. Applied and Environmental Microbiology, 82, 1846-1858 https://doi.org/10.1128/aem.03332-15 (2016).

15. Lowenstein, T. K. \& Risacher, F. Closed Basin Brine Evolution and the Influence of Ca-Cl Inflow Waters: Death Valley and Bristol Dry Lake California, Qaidam Basin, China, and Salar de Atacama, Chile. Aquat. Geochem, 15, 71-94 (2009).

16. Wei, H. C., Qi-Shun, F., Fu-Yuan, A., Fa-Shou, S. \& Qin, Z. J. Chemical Elements in Core Sediments of the Qarhan Salt Lake and Palaeoclimate Evolution during 94-9 ka.Acta Geoscientica Sinica(2016).

17. Fan, Q., Ma, H., Ma, Z., Wei, H. \& Han, F. An assessment and comparison of 230Th and AMS 14C ages for lacustrine sediments from Qarhan Salt Lake area in arid western China. Environ. Earth Sci, 71, 1227-1237 https://doi.org/10.1007/s12665-013-2526-5 (2013).

18. Yu, S., Liu, X., Tan, H. \& Cao, G. Sustainable utilization of Qarhan Salt Lake resources. 27-265(Science Press, 2009).

19. Junker, B. H. \& Schreiber, F.Analysis of biological networks.283-304(Analysis of biological networks, 2008).

20. Faust, K. \& Raes, J. Microbial interactions: from networks to models. Nature Reviews Microbiology, 10, 538-550 https://doi.org/10.1038/nrmicro2832 (2012).

21. Behzad, H., Ibarra, M. A., Mineta, K. \& Gojobori, T. Metagenomic studies of the Red Sea., 576, 717-723 https://doi.org/10.1016/j.gene.2015.10.034 (2016).

22. Naghoni, A. et al. Microbial diversity in the hypersaline Lake Meyghan, Iran. Sci. Rep, 7, https://doi.org/10.1038/s41598017-11585-3 (2017).

23. Ben Abdallah, M. et al. Abundance and diversity of prokaryotes in ephemeral hypersaline lake Chott El Jerid using Illumina Miseq sequencing, DGGE and qPCR assays., 22, 811-823 https://doi.org/10.1007/s00792-018-1040-9 (2018).

Page $11 / 20$ 
24. Kambura, A. K. et al. Bacteria and Archaea diversity within the hot springs of Lake Magadi and Little Magadi in Kenya. BMC Microbiology, 16, https://doi.org/10.1186/s12866-016-0748-x (2016).

25. Paul, D. et al. Exploration of Microbial Diversity and Community Structure of Lonar Lake: The Only Hypersaline Meteorite Crater Lake within Basalt Rock. Frontiers in Microbiology, 6, https://doi.org/10.3389/fmicb.2015.01553 (2016).

26. Cycil, L. M. et al. Metagenomic Insights Into the Diversity of Halophilic Microorganisms Indigenous to the Karak Salt Mine, Pakistan. Frontiers in Microbiology, 11, https://doi.org/10.3389/fmicb.2020.01567 (2020).

27. Jacob, J. H., Hussein, E. I., Shakhatreh, M. A. K. \& Cornelison, C. T. Microbial community analysis of the hypersaline water of the Dead Sea using high-throughput amplicon sequencing. MicrobiologyOpen, 6, e00500 https://doi.org/10.1002/mbo3.500 (2017).

28. Ventosa, A., de la Haba, R. R., Sánchez-Porro, C. \& Papke, R. T. Microbial diversity of hypersaline environments: a metagenomic approach. Current Opinion in Microbiology, 25, 80-87 https://doi.org/10.1016/j.mib.2015.05.002 (2015).

29. Liu, F. H. et al. Bacterial and archaeal assemblages in sediments of a large shallow freshwater lake, Lake Taihu, as revealed by denaturing gradient gel electrophoresis. Journal of Applied Microbiology, 106, 1022-1032 https://doi.org/10.1111/j.1365-2672.2008.04069.x (2009).

30. Song, H., Li, Z., Du, B., Wang, G. \& Ding, Y. Bacterial communities in sediments of the shallow Lake Dongping in China. Journal of Applied Microbiology, 112, 79-89 https://doi.org/10.1111/j.1365-2672.2011.05187.x (2012).

31. Wu, Q. L., Zwart, G., Schauer, M., Agterveld, K. V. \& Hahn, M. W. Bacterioplankton community composition along a salinity gradient of sixteen high-mountain lakes located on the Tibetan Plateau, China. Applied and Environmental Microbiology, 72 , 5478-5485 (2006).

32. Xing, P., Hahn, M. W. \& Wu, Q. L. Low Taxon Richness of Bacterioplankton in High-Altitude Lakes of the Eastern Tibetan Plateau, with a Predominance of Bacteroidetes and Synechococcus spp. Applied and Environmental Microbiology, 75, 7017-7025 https://doi.org/10.1128/aem.01544-09 (2009).

33. Liu, Y. et al. Bacterial Diversity of Freshwater Alpine Lake Puma Yumco on the Tibetan Plateau. Geomicrobiol J, 26, 131145 https://doi.org/10.1080/01490450802660201 (2009).

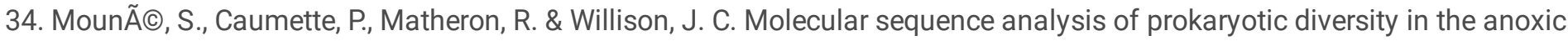
sediments underlying cyanobacterial mats of two hypersaline ponds in Mediterranean salterns. FEMS Microbiology Ecology, 44, 117-130 https://doi.org/10.1016/s0168-6496(03)00017-5 (2003).

35. Valenzuela-Encinas, C. et al. Changes in the bacterial populations of the highly alkaline saline soil of the former lake Texcoco (Mexico) following flooding., 13, 609-621 https://doi.org/10.1007/s00792-009-0244-4 (2009).

36. Kim, T. J., Lee, E. Y., Kim, Y. J., Cho, K. S. \& Ryu, H. W. Degradation of polyaromatic hydrocarbons by Burkholderia cepacia 2A-12. World Journal of Microbiology \& Biotechnology, 19, 411-417 https://doi.org/10.1023/A:1023998719787 (2003).

37. Gales, G. et al. Preservation of ancestral Cretaceous microflora recovered from a hypersaline oil reservoir. Sci. Rep, 6, https://doi.org/10.1038/srep22960 (2016).

38. Kleinsteuber, S., Riis, V., Fetzer, I., Harms, H. \& Müller, S. Population Dynamics within a Microbial Consortium during Growth on Diesel Fuel in Saline Environments. Applied and Environmental Microbiology, 72, 3531-3542 https://doi.org/10.1128/aem.72.5.3531-3542.2006 (2006).

39. Valenzuela-Encinas, C. et al. The Archaeal Diversity and Population in a Drained Alkaline Saline Soil of the Former Lake Texcoco (Mexico). Geomicrobiol J, 29, 18-22 https://doi.org/10.1080/01490451.2010.520075 (2012).

40. He, S., Tan, J., Hu, W. \& Mo, C. Diversity of Archaea and Its Correlation with Environmental Factors in the Ebinur Lake Wetland. Curr. Microbiol, 76, 1417-1424 https://doi.org/10.1007/s00284-019-01768-8 (2019).

41. Sandaa, R. A., Enger, O. \& Torsvik, V. Abundance and diversity of Archaea in heavy-metal-contaminated soils. Applied \& Environmental Microbiology, 65, 3293-3297 (1999).

42. Dave, B. P. \& Soni, A. Diversity of Halophilic Archaea at Salt Pans Around Bhavnagar Coast, Gujarat. Proceedings of the National Academy of Sciences, India Section B: Biological Sciences 83, 225-232, doi:10.1007/s40011-012-0124-z (2012). 
43. Zafrilla, B., Martínez-Espinosa, R., Alonso, M. A. \& Bonete, M. J. Biodiversity of Archaea and floral of two inland saltern ecosystems in the Alto Vinalopó Valley, Spain. Saline Systems, 6, 10 (2010).

44. Costa, M., Santos, H. \& Galinski, E. A. An overview of the role and diversity of compatible solutes in Bacteria and Archaea. Advances in Biochemical Engineering/biotechnology, 61, 117 (1998).

45. Williams, R. J., Howe, A. \& Hofmockel, K. S. Demonstrating microbial co-occurrence pattern analyses within and between ecosystems. Frontiers in Microbiology, 5, https://doi.org/10.3389/fmicb.2014.00358 (2014).

46. Schmidt, T. S. B., Rodrigues, M., von Mering, C. \& J. F. \& A family of interaction-adjusted indices of community similarity. The ISME Journal, 11, 791-807 https://doi.org/10.1038/ismej.2016.139 (2016).

47. Oyewusi, H. A. et al. Functional profiling of bacterial communities in Lake Tuz using 16S rRNA gene sequences. Biotechnology \& Biotechnological Equipment, 35, 1-10 https://doi.org/10.1080/13102818.2020.1840437 (2020).

48. He, C. et al. Synergistic effect of magnetite and zero-valent iron on anaerobic degradation and methanogenesis of phenol. Bioresour. Technol, 291, 121874 https://doi.org/10.1016/j.biortech.2019.121874 (2019).

49. Caporaso, J. G. et al. QIIME allows analysis of high-throughput community sequencing data. Nature Methods, 7, 335-336 https://doi.org/10.1038/nmeth.f.303 (2010).

50. Martin, M. Cutadapt removes adapter sequences from high-throughput sequencing reads. Embnet Journal, 17, 10-12 (2011).

51. Zhang, J., Kassian, K., Tomáš, F. \& Alexandros, S. PEAR: a fast and accurate Illumina Paired-End reAd mergeR.Bioinformatics,614(2014).

52. Robert, S. \& Edwards. Quality control and preprocessing of metagenomic datasets., 27, 863-864 (2011).

53. Edgar, R. C. UPARSE: highly accurate OTU sequences from microbial amplicon reads. Nature Methods, 10, 996-1000 (2013).

54. Schloss, P. D. et al. Introducing mothur: Open-Source, Platform-Independent, Community-Supported Software for Describing and Comparing Microbial Communities. Applied \& Environmental Microbiology, 75, 7537 (2009).

55. Chen, H. \& Boutros, P. C. VennDiagram: a package for the generation of highly-customizable Venn and Euler diagrams in R. BMC Bioinformatics, 12, https://doi.org/10.1186/1471-2105-12-35 (2011).

56. McArdle et al. Fitting multivariate models to community data: a comment on distance-based redundancy analysis., $\mathbf{8 2}$, 290-290 (2001).

57. Langille, M. G. I. et al. Predictive functional profiling of microbial communities using 16S rRNA marker gene sequences. Nature Biotechnology, 31, 814-821 https://doi.org/10.1038/nbt.2676 (2013).

58. Louca, S. \& Doebeli, M. Efficient comparative phylogenetics on large trees., 34, 1-3 (2017).

59. Louca, S., Parfrey, L. W. \& Doebeli, M. Decoupling function and taxonomy in the global ocean microbiome., 353, 1272 (2016).

\section{Figures}



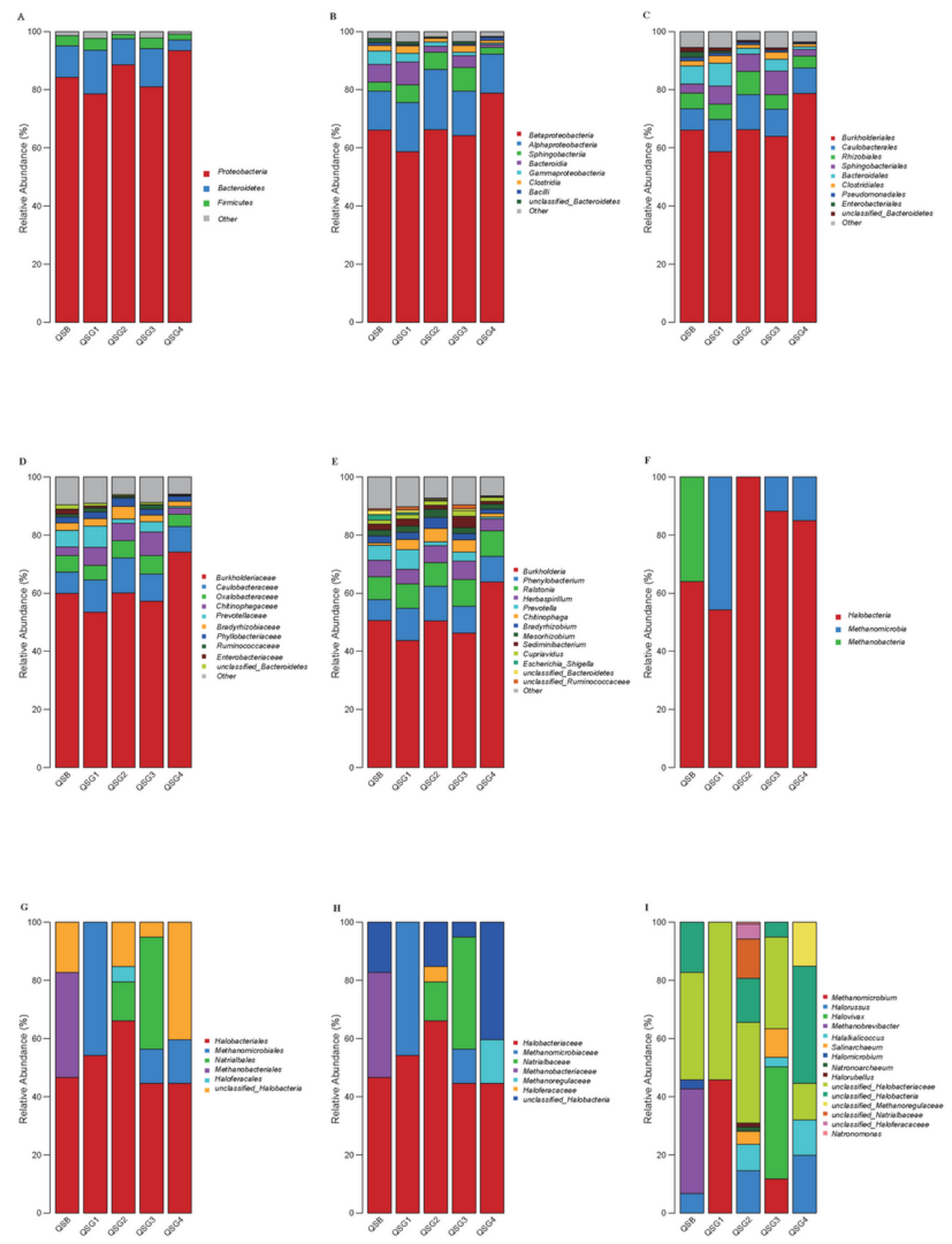

\section{Figure 1}

Relative abundance of prokaryotic microorganisms at different taxonomic units in soils around the Chaerhan Salt Lake. A: Bacteria Phylum, B: Bacteria Class, C: Bacteria Order, D: Bacteria Family, E: Bacteria Genus, F: Archaea Class, G: Archaea Order, $\mathrm{H}$ : Archaea Family, and I: Archaea Genus). Groups occupying less than $1 \%$ of the distribution were clubbed together and designated as 'Others'. 
A

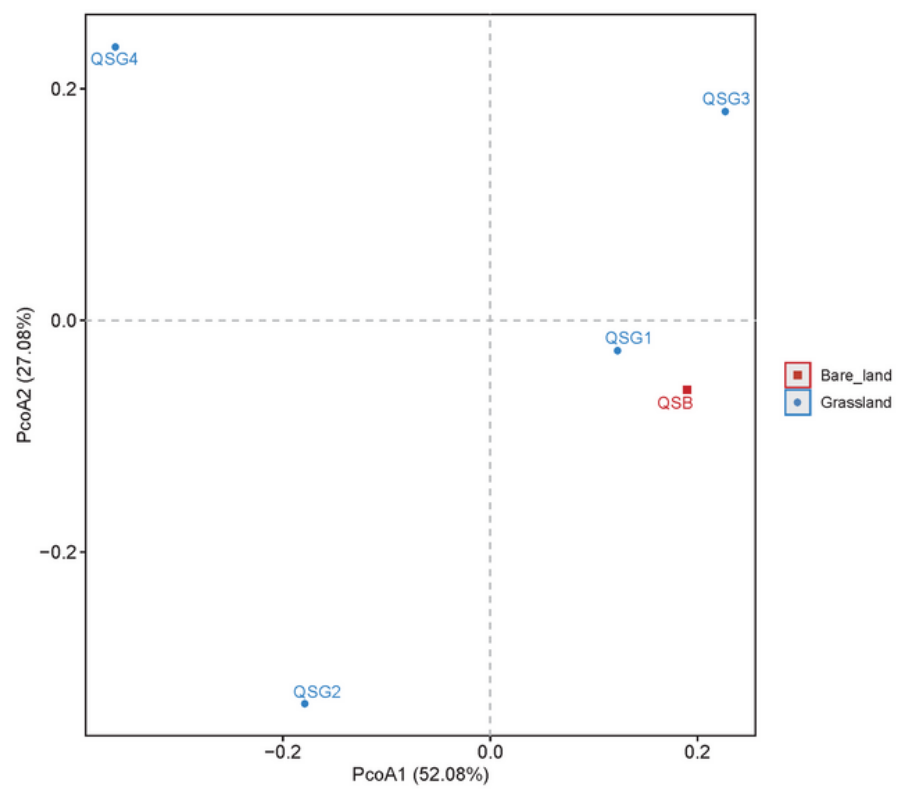

B

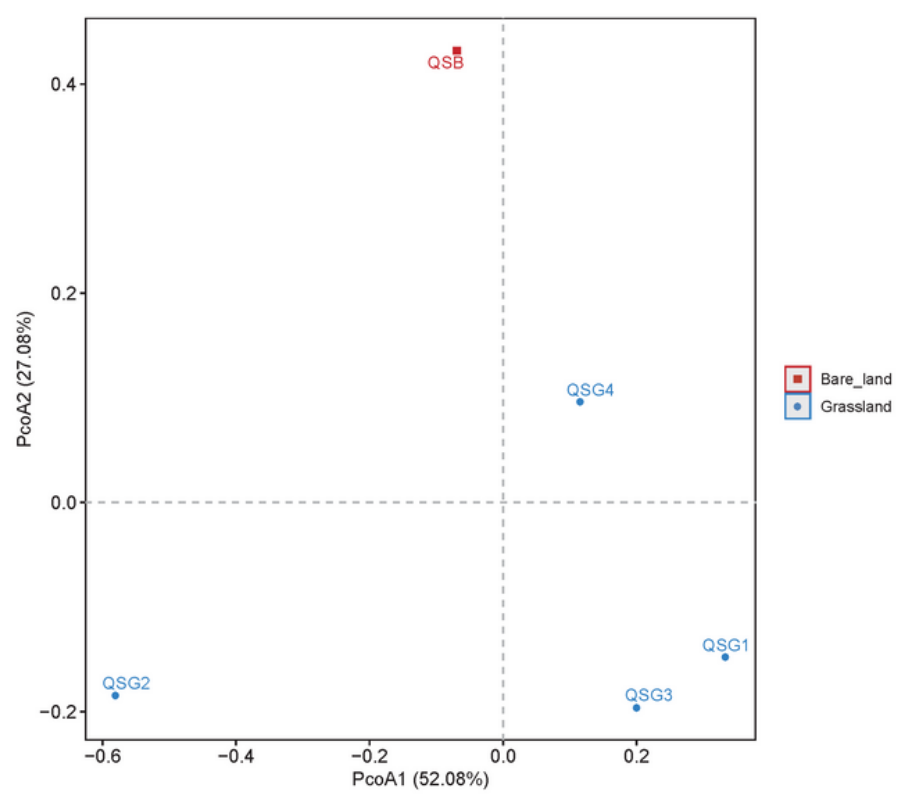

\section{Figure 2}

Principal coordinate (Unweighted Unifrac) plot showing the $\beta$-diversity of bacterial (A) and archaeal (B) communities in soils around the Chaerhan Salt Lake. 
A

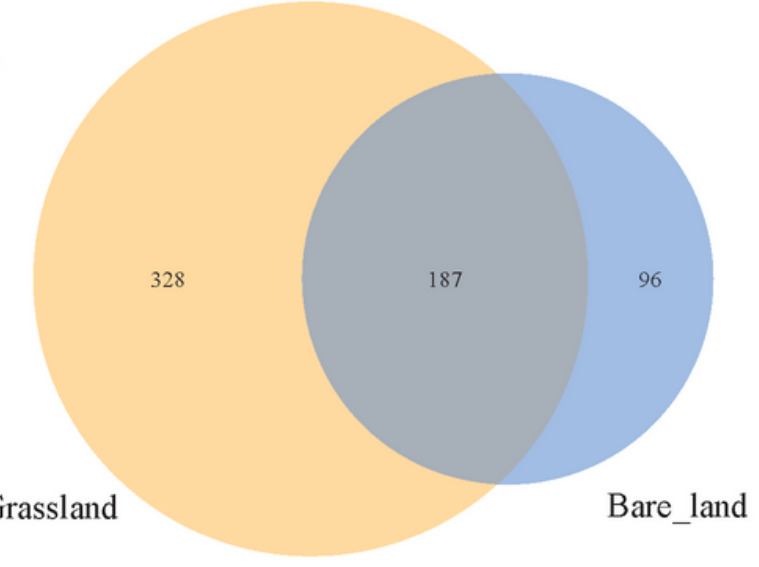

B

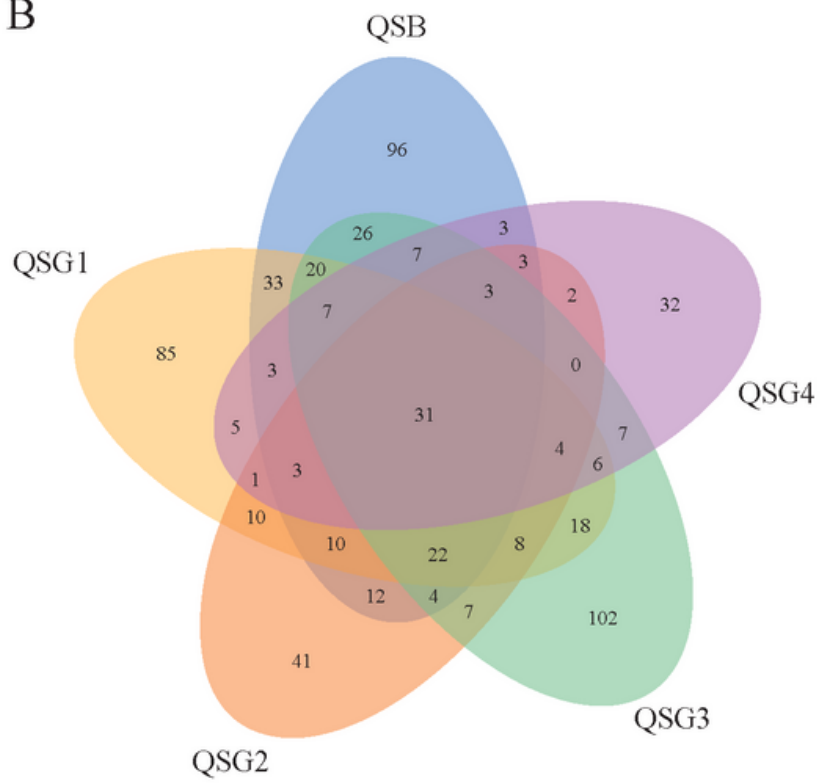

$\mathrm{C}$

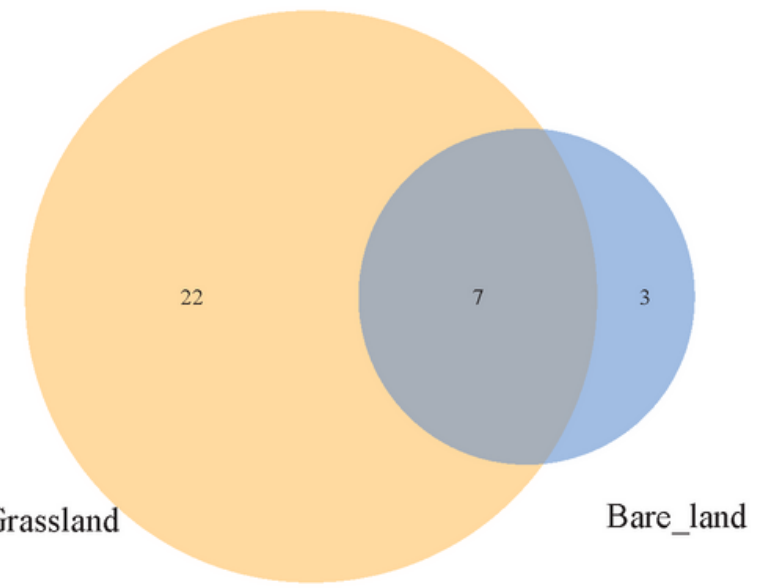

$\mathrm{D}$

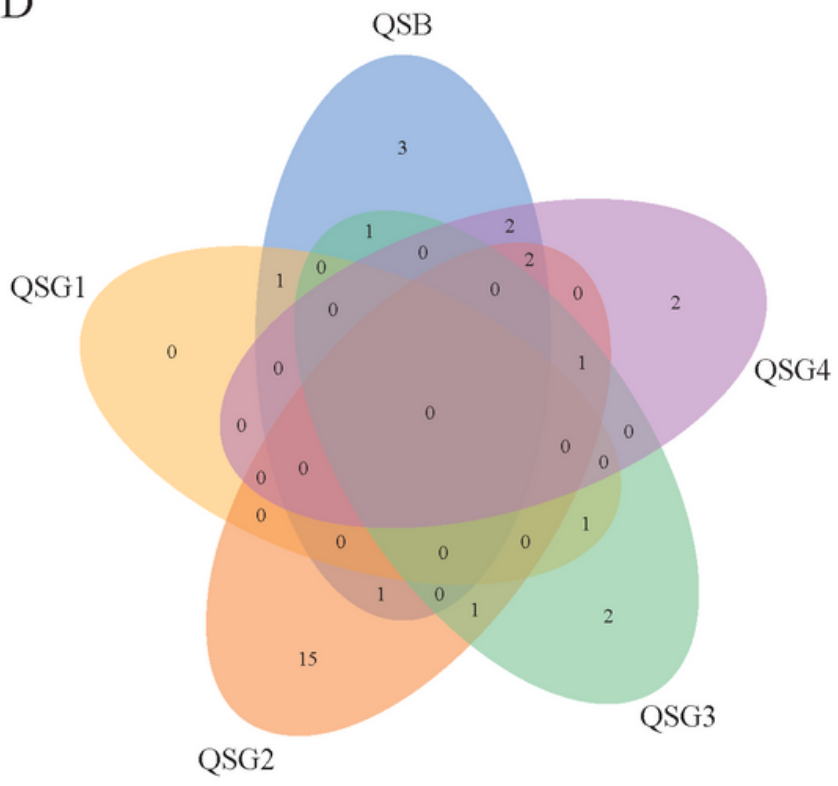

\section{Figure 3}

Venn diagram showing the number of shared and unique bacterial $(A, B)$ and archaeal $(C, D)$ OTUs in soils around the Chaerhan Salt Lake. 
A

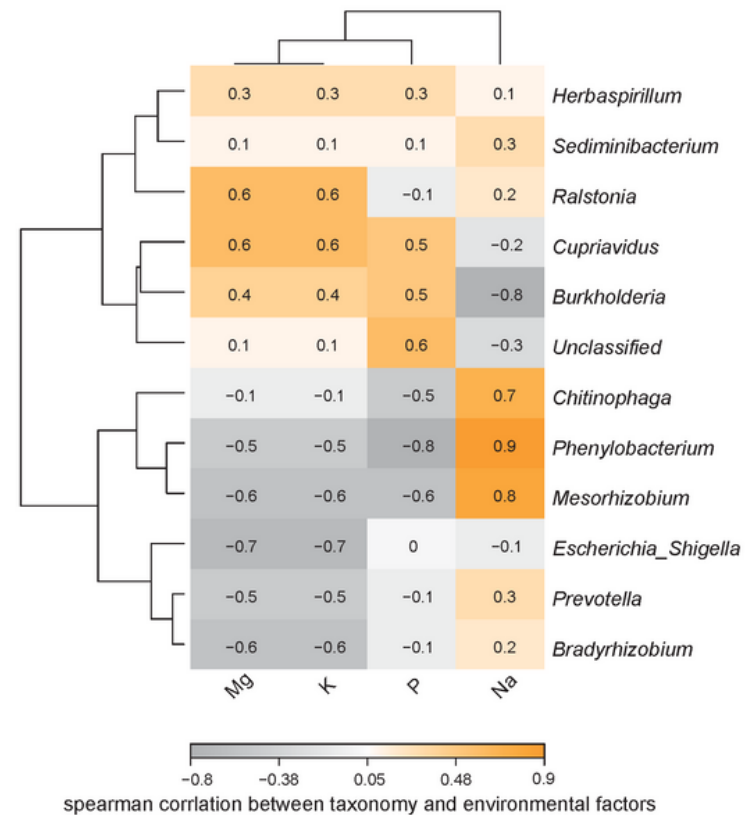

B

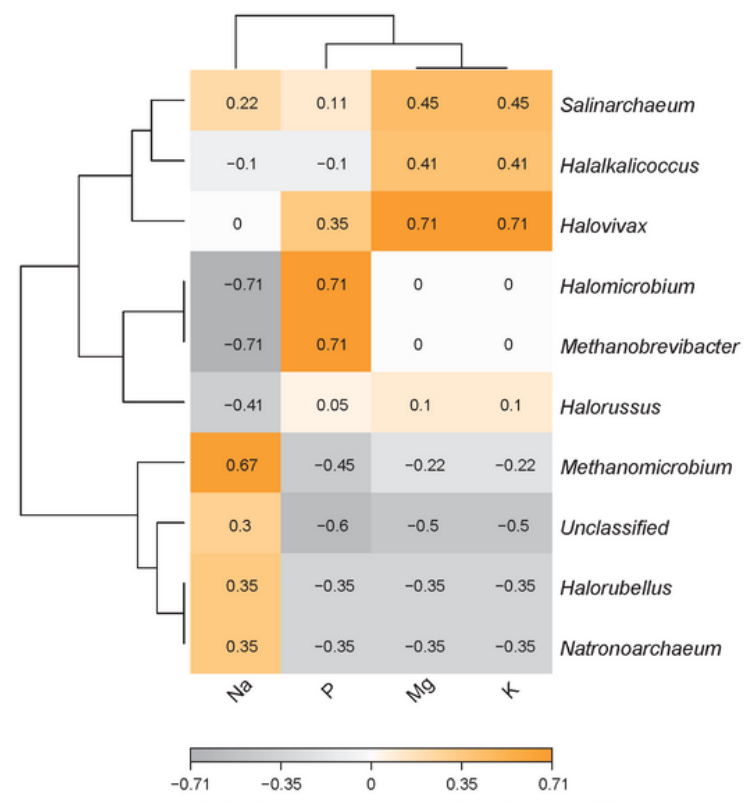

spearman corrlation between taxonomy and environmental factors

\section{Figure 4}

Heatmap of the bacterial (A) and archaeal (B) environment-sensitivity at the genus level in soils around the Chaerhan Salt Lake. 
A

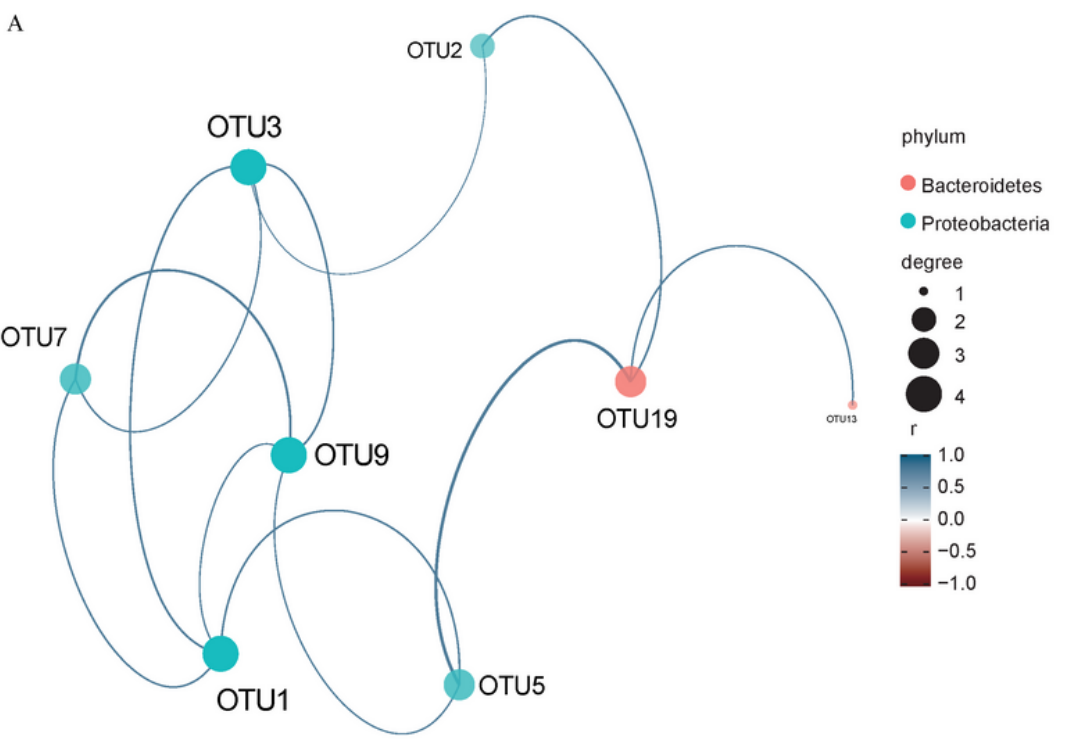

B

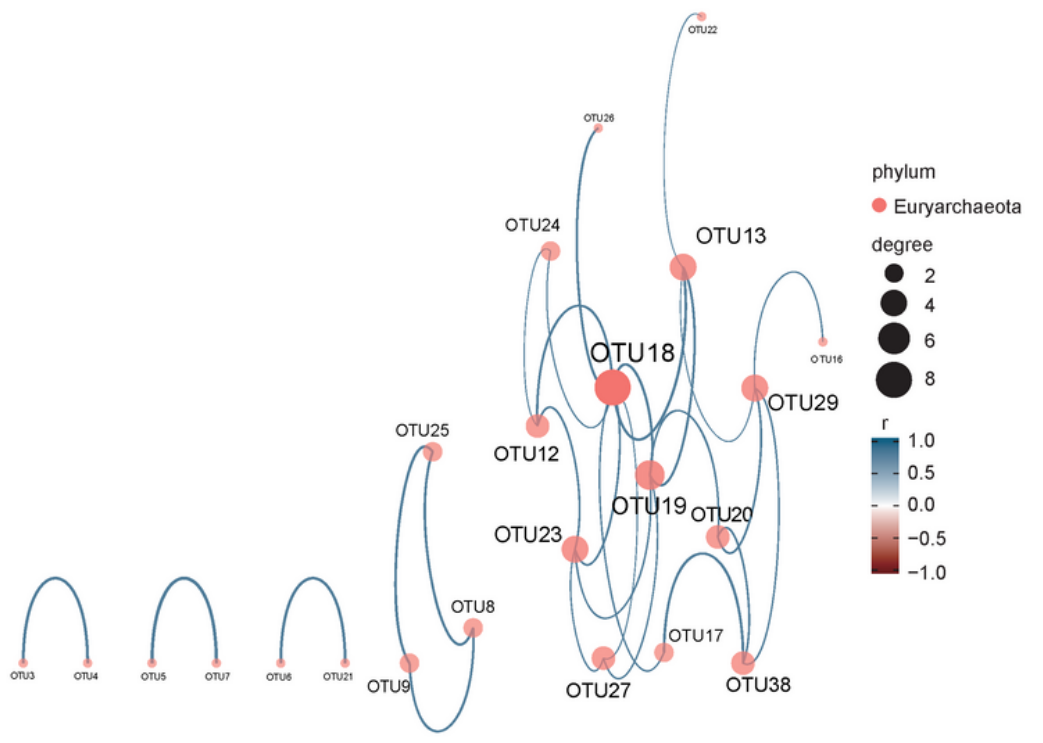

\section{Figure 5}

Bacterial (A) and archaeal (B) networks were constructed by calculating the correlations between species representing significant co-occurrence relationships among abundance of clades on OTU level in soils around Chaerhan Salt Lake. The size of nodes in the figure represents the Degree of connectivity of species, and different colors represent different gates. The colors of the lines indicate positive or negative correlations; the thickness of the line indicates the correlation coefficient, and the thicker the line is, the higher the correlation between species. The more lines, the closer the relationship between the species and other species. Only P-values less than 0.05 and absolute values of correlation greater than 0.8 are shown in the figures. 

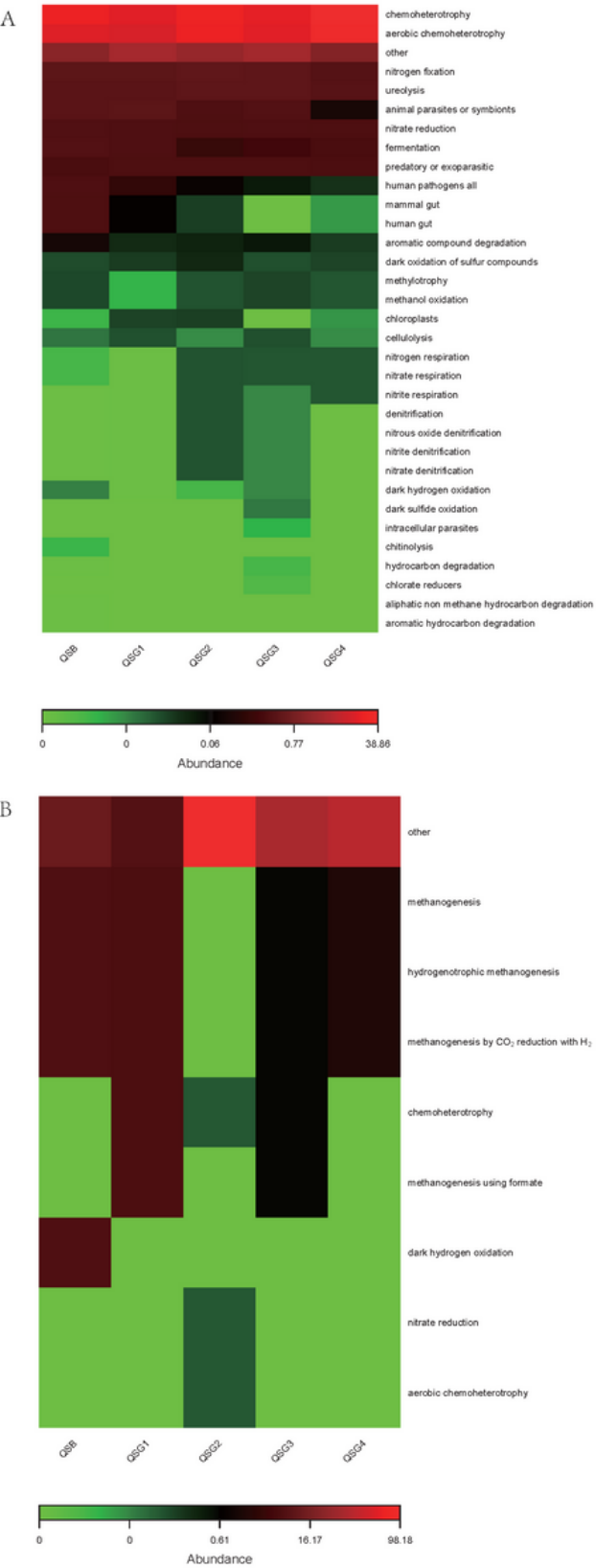

\section{Figure 6}

Functional community heatmap. Predict gene families based on prokaryotic metagenomes by modelling genes from 16S rRNA data derived from the generated OTUs and its reference genome database using FAPROTAX (A - Bacteria and B - Archaea). Red colors correspond to higher relative abundances. 


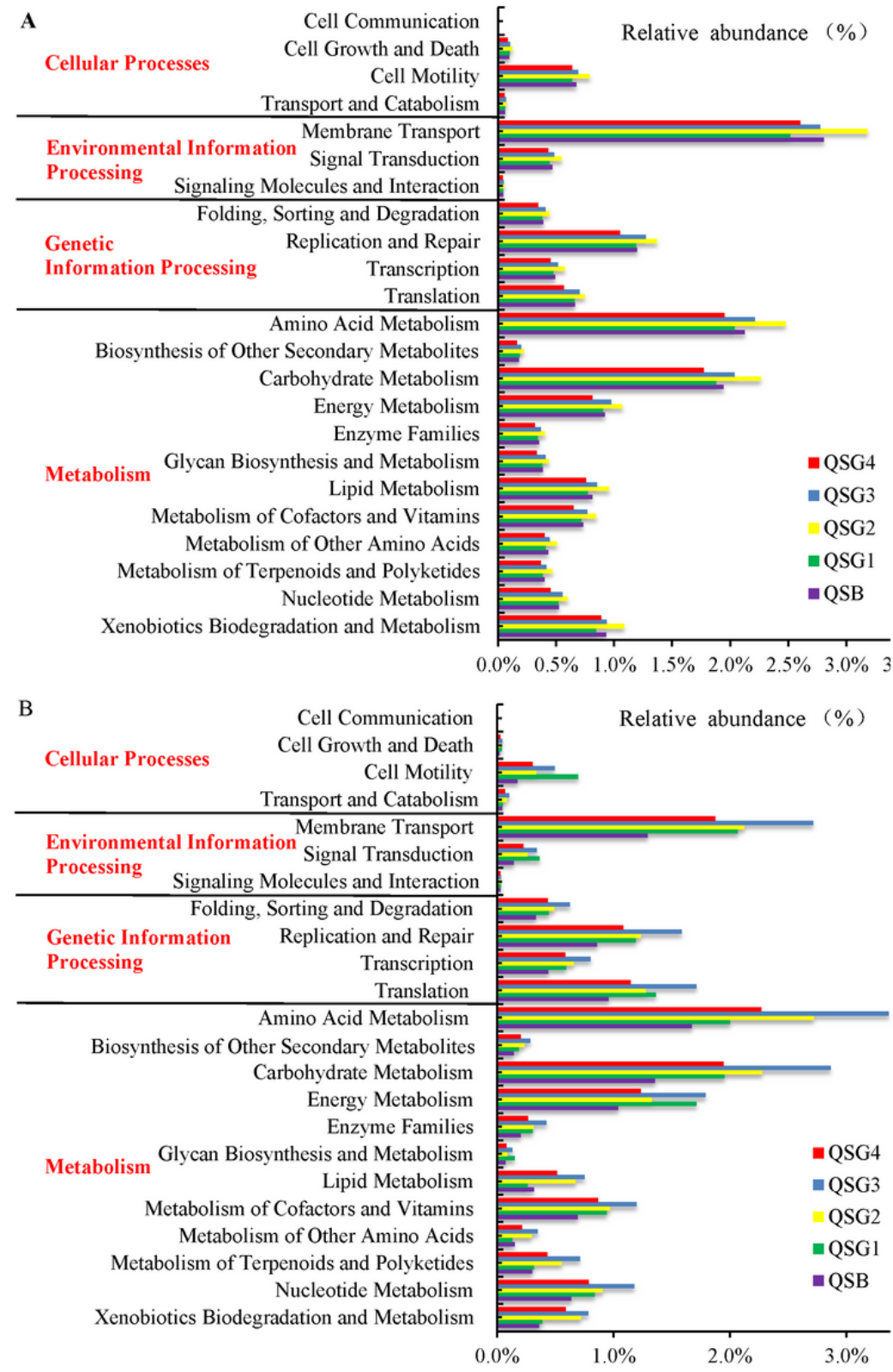

\section{Figure 7}

Relative abundances of metabolic pathways on KEGG categories (level 2) (A - Bacteria and B - Archaea).

\section{Supplementary Files}

This is a list of supplementary files associated with this preprint. Click to download.

- Supplementaryinformation.pdf 